\title{
ANALISIS KINERJA PROYEK PEMBANGUNAN RUMAH SAKIT BANYUMANIK II DENGAN MENGGUNAKAN EARNED VALUE ANALYSIS (EVA) DAN PROJECT EVALUATION REVIEW TECHNIQUE (PERT)
}

\author{
Aries Susanty ${ }^{*}$, Adi Luhung Pekerti*), Diana Puspita Sari \\ Program Studi Teknik Industri, Fakultas Teknik, Universitas Diponegoro \\ Jl. Prof. Soedharto SH Tembalang, Semarang 50239
}

(Received: March 23, 2016 / Accepted: June24, 2016)

\begin{abstract}
Abstrak
Penelitian ini bertujuan untuk untuk mengevaluasi kinerja proyek pembangunan Rumah Sakit Banyumanik II serta memberikan rekomendasi penjadwalan ulang atas pelaksanaan proyek teresebut. Penilaian kinerja proyek pembangunan Rumah Sakit Banyumanik II akan dilakukan dengan menggunakan Earned Value Analysis (EVA), sedangkan penjadwalan ulang atas pelaksanaan pekerjaan proyek tersebut akan dilakukan dengan menggunakan metoda Project Evaluation and Review Technique (PERT). Hasil penilaian kinerja proyek dengan menggunakan EVA menunjukkan bahwa pada hari 315, kinerja proyek kurang baik. Perbandingan antara estimasi nilai (value) pekerjaan fisik yang sebenarnya yang telah selesai dengan porsi total estimasi biaya yang sudah disetujui untuk dikeluarkan untuk proyek selama 315 hari (scheduling performance index) memiliki nilai kurang dari 1 (76,8\%). Pengerjaan proyek tertinggal dari jadwal yang telah ditetapkan. Perbandingan nilai antara estimasi nilai (value) pekerjaan fisik yang sebenarnya yang telah selesai dengan biaya total langsung maupun tidak langsung yang digunakan dalam rangka menyelesaikan proyek sesuai aktivitasnya (cost performance index) selama 315 hari memiliki nilai kurang dari $1(91,8 \%)$. Biaya proyek melebihi biaya yang dianggarkan sampai dengan periode tersebut. Selanjutnya, terdapat beberapa skenario untuk penyelesaian proyek apabila penjadwalan ulang atas sisa kegiatan dari proyek dilakukan dengan mengacu pada kondisi proyek pada hari ke-315. Jika sisa kegiatan proyek dipercepat dan proyek dapat diselesaikan dalam kurun waktu 117 hari, maka total biaya yang diperlukan adalah Rp.4.787.828.482, Jika sisa kegiatan proyek dipercepat dan proyek dapat diselesaikan dalam kurun waktu 113 hari, maka biaya yang diperlukan adalah Rp 4.800.288.482, Jika sisa kegiatan proyek dipercepat dan proyek dapat diselesaikan dalam kurun waktu 103 hari, maka biaya yang diperlukan adalah Rp.5.014.688.482. Jika sisa kegiatan proyek dipercepat dan proyek dapat diselesaikan dalam kurun waktu 102 hari, maka baiya yang diperlukan adalah Rp.5.053.453.482; dan jika sia kegiatan proyek dipercepat dan proyek dapat diselesaikan dalam kurun waktu 94 hari maka biaya yang diperlukana adalah Rp.5.397.573.482.
\end{abstract}

Kata Kunci : earned value analysis; project evaluation and review technique; rumah sakit banyumanik II

\begin{abstract}
This study aims to evaluate the performance of the construction project of Banyumanik II Hospital and provide some recommendations for project rescheduling. Earned Value Analysis (EVA) is used as a method for evaluating a project performance; whereas, Project Evaluation and Review Technique (PERT)are used as a method for project rescheduling. The result of the evaluation of project performance using EVA shows that the construction project of Banyumanik Hospital II has poor performance on day 315. The comparison between the estimation of the original budget that has been earned by actual work completed and the planned time-phased baseline of the value of the work scheduled (scheduling performance index) on day 315 less than 1 (76.8\%). Its mean the project behind the schedule. The comparison between the estimation of the original budget that has been earned by actual work completed
\end{abstract}

\footnotetext{
${ }^{*}$ Penulis Korespondensi. email: ariessusanty@gmail.com; adi.luhung.pekerti@gmail.com
} 
and actual cost of the work completed on day 315 also less than 1 (91,8\%. Its mean the project over cost. Then, based on the condition of the construction project on day 315, we can make some scenario of project completion. If the project is completed in 117 days, the total cost for remaining activity will be IDR 4.787.828.482. If the project is completed in 113 days, the total cost for remaining activity will be IDR. 4.800.288.482, If the project is completed in 103 days, the total cost for remaining activity will be IDR. 5.014.688.482. If the project is completed in 102 day, the total cost for remaining activity will be Rp.5.053.453.482; and if the project is completed in 94 days, the total cost for remaining activity will be IDR. 5.397.573.482.

Keywords: earned value analysis; project evaluation and review technique; rumah sakit banyumanik II

\section{Pendahuluan}

Dewasa ini, proyek konstruksi berkembang dengan pesat dan memiliki kerumitan yang tinggi, baik dari segi fisik maupun biaya. Secara harfiah, suatu kegiatan proyek adalah suatu kegiatan yang berlangsung dalam jangka waktu tertentu dengan alokasi sumber daya yang terbatas. Di dalam dunia industri, khususnya bidang konstruksi, banyaknya proyek yang berjalan melebihi anggaran dan jadwal yang tetapkan merupakan suatu indikasi bahwa terdapat sesuatu yang salah dalam pengelolaan proyek tersebut (Khamooshi dan Golafshani, 2014). Untuk mengatasi masalah tersebut, dibutuhkan pengelolaan proyek yang baik melalui manajemen proyek. Dalam hal ini, peningkatan sistem pengelolaan proyek yang baik dan terintegrasi serta pengelolaan seluruh tahapan siklus proyek dengan melihat penjadwalan dan performansi suatu proyek akan semakin dibutuhkan sejalan dengan semakin tingginya kompleksitas suatu proyek dan semakin langkanya sumber daya yang dibutuhkan (Naderpour dan Mofid,2011).

Terdapat sejumlah perusahaan di Semarang yang mengkhususkan diri untuk mengerjakan proyekproyek konstruksi. Salah satunya adalah PT. Tiga Pilar Kilau Kencana atau disingkat menjadi Tiga Pilar. Selama ini, Tiga Pilar menggunakan pendekatan time based competition untuk menyelesaikan proyek-proyek yang ditanganinya dan menggunakan pendekatan time phased budget untuk penyusunan anggaran proyek dimana perkiraan biaya proyek dikaitkan dengan rencana jadwal pelaksanaan pekerjaan yang disebut Anggaran Rencana Pelaksanaan (ARP). Pada pendekatan time based competition, variabel jadwal menjadi kompetensi utama dan pelaksanaan proyek menekankan pada pencapaian titik-titik penting dari suatu proyek dan penyelesaian tepat waktu (Shtub dkk, 1994). Tiga pilar menggunakan pendekatan time based competition untuk menyeleaikan proyek-proyek yang ditanganinya dengan alasan bahwa keterlambatan terhadap jadwal yang telah ditetapkan akan mengakibatkan sejumlah kerugian yang harus ditanggung oleh perusahaan, antara lain penambahan biaya dan kehilangan kesempatan untuk memasuki pasar. Disamping pendekatan time based competition, pendekatan lainnya yang dapat digunakan untuk menyelesaikan suatu proyek adalah pendekatan cost based competition dan quality based competition. Pendekatan cost based competition lebih menekankan pada anggaran proyek yang serendah mungkin dan pengontrolan yang ketat terhadap anggaran proyek; sedangkan pendekatan cost based competition lebih menekankan pada pengendalian kualitas total dari proyek yang dikerjakan (Shtub dkk, 1994). Selanjutnya, untuk menjamin ketepatan jadwal pekerjaan dan kesesuaian biaya yang dikeluarkan dengan anggaran, Tiga Pilar selalu mengevaluasi jadwal pelaksanaan pekerjaan dan biaya yang dikeluarkan secara berkala. Dalam hal ini, Tiga Pilar senantiasa membandingkan antara kemajuan proyek secara fisik saat ini (aktual) dan yang direncanakan.

Salah satu proyek pekerjaan konstruksi yang saat ini sedang dikerjakan oleh Tiga Pilar adalah pembangunan Rumah Sakit Banyumanik II. Hasil evaluasi awal antara kemajuan proyek Rumah Sakit Banyumanik II secara aktual dan rencana menunjukkan kondisi yang kurang baik.. Sejak minggu ke-13 sampai dengan mingu ke-21 atau selama 8 minggu secara berturut-turut, proyek mengalami keterlambatan. Kondisi ini membuat Tiga Pilar merasa perlu melakukan evaluasi lebih detil atas kinerja waktu dan biaya dari proyek pembangunan Rumah Sakit II Banyumanik sebagai early warning untuk menilai adanya ketidakefisienan dalam penyelesaian proyek Rumah Sakit Banyumanik II. Dalam hal ini eveluasi atas kinerja waktu dan biaya tersebut akan dilakukan dengan menggunakan pendekatan Earned Value Analysis (EVA). Selanjutnya, berdasarkan hasil dari evaluasi atas kinerja waktu dan biaya, Tiga Pilar akan melakukan penjadwalan ulang atas proyek pembangunan Rumah Sakit Banyumanik II untuk mempercepat pelaksanaan proyek agar dapat selesai pada waktu yang telah ditentukan dengan biaya tertentu. Dalam hal ini, pendekatan yang digunakan untuk penjadwalan ulang atas proyek Rumah Sakit Bnayumanik II adalah Program Evaluation and Review Technique (PERT). EVA dan PERT memiliki perbedaan fokus, EVA fokus pada pengontrolan dari suatu proyek. EVA merupakan suatu metoda yang digunakan untuk menentukan status dari proyek (apakah proyek tersebut melebihi atau tertinggal dari jadwal yang telah ditetapkan atau apakah biaya aktual dari proyek tersebut melebihi 
atau dibawah anggaran yang telah ditetapkan). Lebih jauh, berdasrkan tren yang terjadi saat ini, EVA memungkinkan seorang manajer proyek untuk membuat tindakan agar waktu dan biaya dari suatu proyek dapat sesuai dengan yang telah ditetapkan (Burke, 2006). Adapun PERT memiliki fokus pada penjadwalan suatu proyek melalui koordinasi dan sinkronisasi semua elemen yang merupakan bagian dari proyek dan menyelesaikan proyek secepat mungkin. Metoda PERT memungkinkan untuk mengestimasi dampak dari ketidakpastian waktu dari penyelesaian setiap pekerjaan dari poyek yang berdampak pada ketidapaktian durasi proyek secara keseluruhan (Hall, 2012)

\section{Tinjauan Pustaka}

\section{Pengertian Proyek}

Menurut PMBOK Guide (2000) proyek adalah suatu upaya yang bersifat sementara yang dilakukan untuk membuat suatu produk, layanan, atau hasil yang unik. Pengertian ini disempurkanakan oleh Cleland dan Ireland (1994) yang mengatakan bahwa proyek adalah gabungan dari berbagai sumber daya yang dihimpun dalam uatu wadah organisasi sementara untuk mencapai suatu tujuan tertentu. Adapun menurut Ervianto dan Wulfram (2004), kegiatan proyek dapat diartikan sebagai suatu kegiatan sementara yang berlangsung dalam jangka waktu terbatas, dengan alokasi sumber daya terbatas dan dimaksudkan untuk melaksanakan tugas yang sasarannya telah digariskan dengan jelas.

\section{Triple Constraint}

Menurut Larson dan Gray (2011), terdapat tiga buah batasan yang mengikat sebuah proyek, yaitu waktu, biaya, dan kebutuhan performa. Ketiga batasan itu dikenal dengan nama triple constraint. Secara rinci, masing-masing batasan dalam triple constraint dapat dijelaskan sebagai berikut:

a. Waktu: proyek harus dikerjakan dalam kurun waktu dan tanggal akhir yang telah ditentukan. Bila hail akhir adalah produk baru maka penyerahannya tidak boleh melewati batas waktu yang telah ditentukan.

b. Biaya: Proyek harus diselesaikan dengan biaya yang tidak melebihi anggaran yang telah ditetapkan.

c. Kebutuhan performa: hasil kegiatan dari suatu proyek harus memenuhi spesifikasi dan kriteria yang dipersyaratkan. Memenuhi persyaratan mutu berarti mampu memenuhi tugas yang dimaksudkan atau sering disebut sebagai fit for the intended use.

\section{Earned Value Analysis}

Earned value analysis (EVA) merupakan metoda dalam manajemen proyek yang digunakan untuk menentukan status dari proyek (apakah proyek tersebut melebihi atau tertinggal dari jadwal yang telah ditetapkan atau apakah biaya aktual dari proyek tersebut melebihi atau dibawah anggaran yang telah ditetapkan) (Burke, 2006). Disamping dapat digunakan untuk menentukan status dari proyek, EVA juga merupakan metoda yang dapat digunakan untuk memperkirakan biaya dan waktu penyelesaian suatu proyek (Larson dan Gray, 2011). Beberapa istilah dan persamaan yang penting dalam EVA yang dapat digunakan untuk menentukan status dari proyek dapat diuraikan sebagai berikut (Larson dan Gray, 2011; Verma dan Pathak, 2014):

a. Budgeted Cost Work Schedule (BCWS)

BCWS merupakan anggaran biaya yang dialokasikan berdasarkan rencana kerja yang telah disusun terhadap waktu atau perkiraan biaya yang disetujui dari sumber daya yang dijadwalkan berdasarkan waktu. BCWS dapat dinayatakan juga sebagai sebagai planned value (PV)

b. Budgeted Cost Work Performed (BCWP)

BCWP adalah persentase pekerjan yang telah selesai dikalikan dengan biaya yagn telah menjadi anggarannya, atau kemajuan yang telah dicapai berdasarkan nilai uang dari pekerjaan-pekerjaan yang telah diselesaikan pada periode waktu tertentu. BCWP dapat dinyatakan juga sebagai earned value $(\mathrm{EV})$

c. Actual Cost Work Permormed (ACWP)

ACWP adalah biaya aktual yang dikeluarkan untuk menyelesaikan pekerjaan sampai pada periode tertentu. ACWP dapat disajukan per periode atau kumulatif. ACWP dapat dinyatakan juga sebagai actual cost (AC)

d. Budget at Completion (BAC)

BAC adalah anggaran rencana yang akan diserap oleh keseluruhan proyek atau keseluruhan pekerjaan. Nilainya adalah nilai proyek tersebut atau nilai kontrak yang harus diselesaikan atau nilai keseluruhan pekerjaan

e. Schedule Variance (SV); SV merupakan perbedaan antara kemajuan pekerjaan yang dicapai dengan yang direncanakan pada periode tertentu yang menunjukkan posisi kemajuan pekerjaan tersebut pada periode tersebut. $\mathrm{SV}=\mathrm{BCWP}-\mathrm{BCWS}$.

Schedule Variance $=0$; proyek tepat waktu

Schedule Variance > 0 ; proyek lebih cepat

Schedule Variance < 0 ; proyek terlambat

f. Cost Variance (CV); $\mathrm{CV}$ yaitu variansi atau perbedaan atara biaya yang harus dikeluarkan untuk mengerjakan suatu pekerjaan pada periode tertentu dengan kemajuan pekerjaan yang dicapai pada periode tersebut yang menggambarkan posisi keuangan pekerjaan pada periode yang bersangkutan.

$\mathrm{CV}=\mathrm{BCWP}-\mathrm{ACWP}$

Cost Variance $=0$; biaya proyek sesuai rencana

Cost Variance $>0$; biaya lebih kecil dari rencana Cost Variance < 0 ; biaya lebih besar dari rencana

g. Variance at Completion (VAC); VAC adalah variansi biaya yang diperkirakan akan terjadi pada 
saat proyek telah selesai berdasarkan produktifitas terakhir.

$\mathrm{VAC}=\mathrm{BAC}-\mathrm{EAC}$

h. Schedule Peformance Index (SPI). SPI yaitu indeks yang menunjukkan produktivitas (efesiensi jadwal) berdasarkan kemajuan yang dicapainya pada periode tertentu sedangkan SPIcum adalah indeks produktivitas pekerjaan berdasarkan kumulatif kemajuan yang dicapainya sampai periode tertentu.

$\mathrm{SPI}=\mathrm{BCWP} / \mathrm{BCWS}$

SPIcum $=$ BCWPcum $/$ BCWScum .....(.5)

SPI $=1 ;$ proyek tepat waktu

SPI $>1$; proyek tepat waktu

SPI $<1$; proyek terlambat

i. Cost Performance Index (CPI); CPI yaitu indeks yang menunjukkan produktifitas keuangan (efisiensi biaya) atau keuangan berdasarkan penyerapan biaya yang sebenarnya terjadi sampai pada penyerapan proyek berdasarkan penyerapan biaya yang sebenarnya terjadi pada periode tertentu. CPIcum adalah indeks yang menunjukkan produktivitas periode tertentu.

$\mathrm{CPI}=\mathrm{BCWP} / \mathrm{ACWP} \ldots \ldots . .(6)$

CPIcum = BCWPcum $/$ ACWPcum .....(7)

$\mathrm{CPI}=1$; biaya proyek sesuai rencana

$\mathrm{CPI}>1$; biaya lebih kecil dari rencana

$\mathrm{CPI}<1$; biaya lebih besar dari rencana

j. Estimated Cost at Completion (EAC): EAC merupakan total perkiraan biaya aktual proyek sampai dengan saat pelaporan ditambah dengan biaya untuk pekerjaan yang tersisa (Estimated Cost to Complete Remaining Work-ETC).

$\mathrm{EAC}=\mathrm{ACWP}+\mathrm{ETC} \ldots . .(8)$

Adapun besarnya biaya untuk pekerjaan yang tersisa dapat diekstrapolasi dengan beberapa cara sebagai berikut. Bila penyelesaian pekerjaan masih dibawah 50\% maka total biaya proyek (EAC) didapat dengan rumus berikut:

$\mathrm{ETC}=$ Total Biaya Anggaran - BCWP...(9)

Bila penyelesaian pekerjaan pada saat pelaporan sudah lebih dari $50 \%$, maka total biaya proyek (EAC) didapat dengan rumus berikut:

$E T C=\frac{\text { Total biaya anggaran }-\mathrm{BCWP}}{C P I}$

k. Estimate Completion Date (ECD); ECD mengestimasi waiktu penyelesaian proyek. ECD dapat dihitung dengan menggunakan rumus berikut.

$\mathrm{ECD}=\left(\frac{\text { Sisa Waktu }}{\text { SPI }}\right)+$ Waktu Terpakai....(11)

Dengan presentase keterlambatan/percepetan :

$100 \%-\frac{\text { ECD }}{\text { Waktu terpakai }}$.

1. To Complete Performance Index (TCPI); TCPI merupakan indeks prestasi penyelesaian suatu pekerjaan.

Perhitungan TCPI berdasarkan BAC:

TCPI $=\frac{B A C-B C W P}{B A C-A C W P}$.

Perhitungan TCPI berdasarkan EAC

Jurnal Teknik Industri, Vol. XI, No. 2, Mei 2016
$\mathrm{TCPI}=\frac{B A C-B C W P}{E A C-A C W P} \ldots$

Bila perhitungan TCPI yang didasarkan pada BAC memiliki angka indeks prestasi lebih dari 1 maka kinerja biaya yang dibutuhkan untuk meyelesaikan proyek sudah sesuai BAC. Apabila, perhitugan TCPI yang didasarkan pada EAC memiliki angka prestasi kurang dari satu, maka kinerja biaya sudah sesuai dengan target untuk menyelesaikan proyek sesuai dengan EAC.

\section{Program Evaluation and Review Technique (PERT)}

Metode PERT ditandai sebagai metode stokastik. Tujuan dari metode ini adalah untuk mengidentifikasi jalur kritis dalam grafik, grafik ini merepresentasikan model dari proyek. Implementai algoritma PERT didasarkan pada metode jalur kritis (CPM) (Doubravský dan Doskocil, 2013)

Beberapa terminologi dalam PERT dapat diuraikan sebagai berikut (Adegoke, 2013).

1. PERT event, suatu titik tanda dimana mulai atau selesainya satu atau lebih kegiatan, ini tidak memerlukan waktu serta sumberdaya, PERT event menandai selesainya satu atau lebih kegiatan dan tidak dapat dicapai sebelum semua kegiatan yang mengarah pada kegiatan ini telah selesai.

2. Predecessor event, sebuah kejadian yang secara langsung mendahului beberapa kegiatan lain tanpa gangguan dari kejadian lain, ini dapat berupa akibat lebih dari satu kegiatan.

3. Successor event, kejadian yang seara langsung mengikuti kejadian lain tampa gangguan dari kejadian lain, ini dapat berupa akibat lebih dari satu kegiatan.

4. PERT activity, merupakan performa nyata dari kegiatan, kegiatan ini memerlukan waktu serta sumber daya, dan dapat dianggap sebagai representasi dari waktu, usaha, serta sumberdaya yang digunakan untuk bergerak dari satu kegiatan ke kegiatan berikutnya.

5. Optimistic time, kemungkinan minimum waktu yang diperlukan untuk menyelesaikan suatu kegiatan, dengan mengasumsikan segala sesuatu dalam kondisi ideal dan lebih baik dari keadaan normal.

6. Pessimistic time, kemungkinan maksimal waktu yang dibutuhkan untuk menyelesaikan suatu kegiatan, dengan mengasumsikan segala sesuatu berjalan tidak sesuai harapan namun tampa terjadinya becana alam.

7. Most likely time, estimasi terbaik waktu yang dibutuhkan untuk menyelesaikan suatu pekerjaan, dengan mengasumsikan segala sesuatu berjalan dengan normal.

8. Expected time, estimasi watu terbaik untuk menyelesaikan suatu pekerjaan dengan mengasumsikan segala sesuatu berjalan dengan normal (implikasinya adalah bahwa expected time merupakan rata-rata waktu yang dibutuhkan oleh suatu kegiatan jika kegiatan tersebut 
dilakukan secara berulang-ulang dalam satu periode waktu

Menurut Vanhoucke (2012) Waktu yang diharapkan t dari distribusi beta dapat didapatkan dengan memberikan bobot pada rata-rata nilai dengan menggunakan rumus:

$\mathrm{t}=\frac{a+4 m+b}{6}$...

Standar deviasi dari durasi kegiatan, yang dapat digunakan untuk mengukur resiko, dapat dihitung dengan menggunakan filosofi interval tiga standar deviasi, sebagai berikut:

$\sigma=\frac{b-a}{6}$.

dimana:

$\mathrm{a}=$ waktu optimis

$\mathrm{m}=$ waktu realistis

$\mathrm{b}=$ waktu pesimis

Rata-rata durasi proyek merupakan jumlah dari seluruh waktu rata-rata kegiatan sepanjang lintasan kritis, dan ini mengikuti distribusi normal. Mengtahui durasi ata-rata proyek dan variansi dari kegiatan menungkinkan untuk menghitung kemungkinan penyelesaian proyek dengan waktu yang spesifik menggunakan tabel statistik standar. Persamaan berikut digunakan untuk menghitung nilai " $Z$ " yang dapat ditemukan pada tabel kurva normal, yang memungkinkan menghitung kemungkinan penyelesaian proyek tepat pada waktunya, persamaannya adalah sebagai berikut:

$\mathrm{Z}=\frac{T_{S}-T_{E}}{\sigma} \ldots . .(.21)$

Dimana :

$T_{E}=$ durasi lintasan kritis

$T_{S}=$ durasi rencana proyek

$\mathrm{Z}=$ probabilitas (memenuhi durasi yang telah ditentukan)

\section{Trade-off Penjadwalan antara Waktu/Biaya}

Terdapat dua jenis waktu yaitu waktu normal maksimum $\left(T_{n}\right)$ dan waktu yang dipercepat $\left(T_{c}\right)$; dan, terdapat dua jenis biaya yaitu biaya yang berhubungan dengan waktu normal untuk penyelesaian suatu proyek $\left(C_{n}\right)$ dan biaya yang berhubungan dengan waktu percepatan untuk suatu proyek $\left(C_{C}\right)$. Kedua jenis waktu dan biaya ini akan digunakan untuk menghitung marginal crash per unit dengan rumus berikut.
Cost Slope $=\frac{\left(C_{C}-C_{n}\right)}{T_{n}-T_{C}}$

Keterangan:

$T_{n} \quad=$ waktu normal

$T_{c} \quad$ = waktu dipercepat

$C_{n} \quad=$ Biaya normal

$C_{C} \quad=$ Biaya dipercepat

\section{Metodologi Penelitian \\ Obyek Penelitian}

Penelitian ini mengambil objek proyek pembangunan Rumah Sakit Banyumanik II yang terletak di Jalan Perintis Kemerdekaan No. 59 Banyumanik, semarang, oleh PT. Tiga Pilar Kilau Kencana. Proyek ini bernilai Rp. 45.960.110.000 dengan RAB pengerjaan struktur sebesar Rp. 19.358.816.791,79. Waktu yang dijadwalkan untuk menyelesaikan proyek ini adalah selama 385 hari terhitung tanggal 29 Desember 2014 hingga 16 Januari 2016

\section{Pengumpulan dan Pengolahan Data}

Pada tahap ini dilakukan pengumpulan dan pengolahan data, dimana data yang dikumpulkan berupa data sekunder dan primer. Data sekunder diambil dari studi literatur, laporan progres proyek, serta rancangan anggaran proyek. Kemudian data primer didapat dari observasi langsung di lapangan, pengukuran yang dilakukan selama 315 hari dari proyek pertama kali dilaksanakan. Setelah data terkumpul, dilakukan pengolahan data dengan metode yang telah ditentukan. Berikut alur pengolahan data :

1. Melakukan pengukuran performansi proyek menggunakan parameter EVA

2. Jika terdapat keterlambatan dari jadwal yang telah ditentukan, maka dilakukan penjadwalan ulang proyek menggunakan PERT

3. Membandingkan hasil penjadwalan ulang proyek dengan jadwal sebelum di lakukan penjadwalan ulang

\section{Hasil Dan Pembahasan}

Activity On Arrow Diagram

Activity on Arrow (AoA) yang menggambarkan urutan kegiatan dalam pelaksanaan proyek pembangunan RS Banyumanik II dapat dilihat pada gambar 1 berikut. Adapun duarai waktu pelaksanaan dari setiap kegiatan proyek pembangunan RS Banyumanik II dapat dilihat pada tabel 1 berikut. 


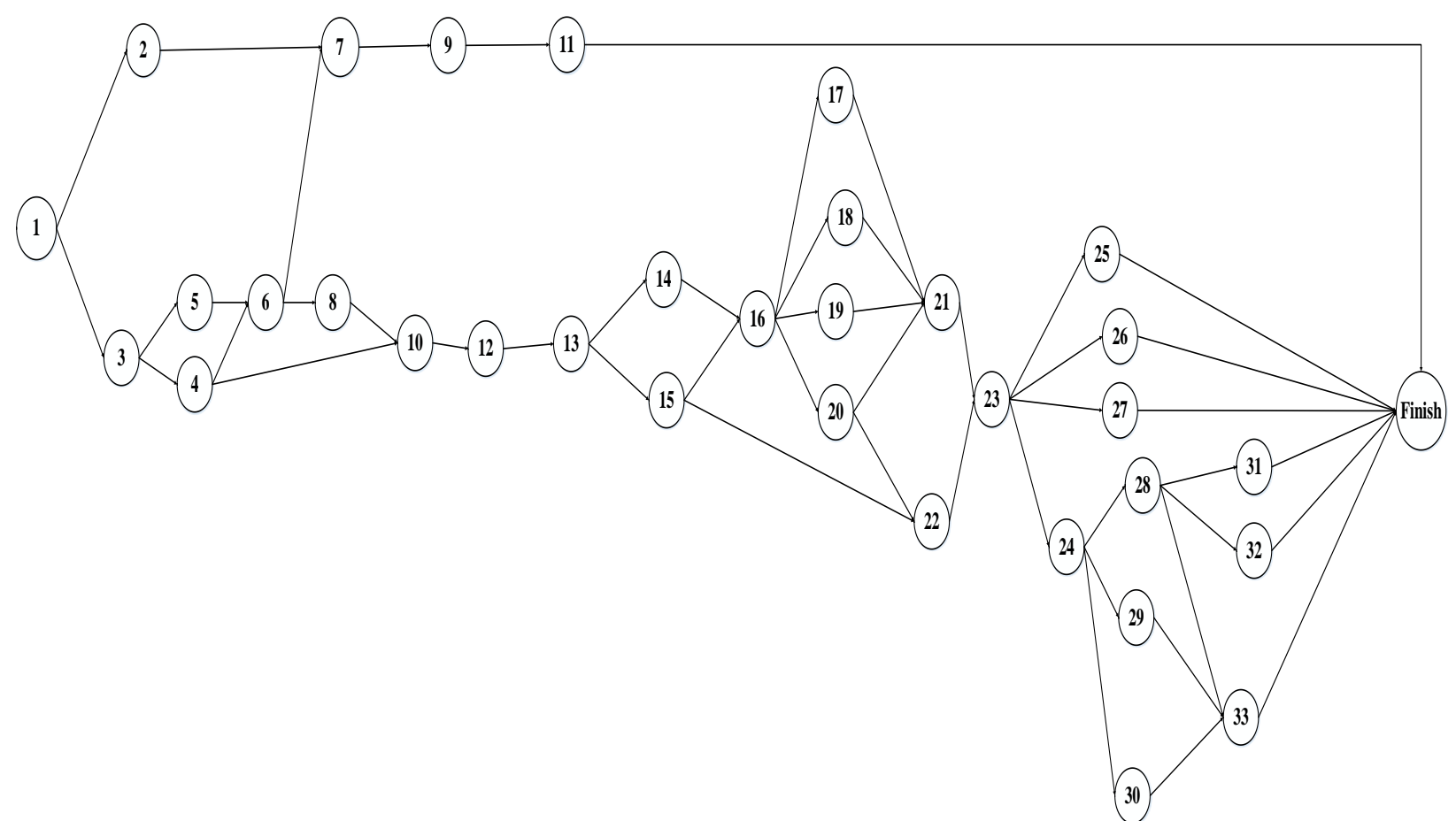

Gambar 1. Activity on Arrow Diagram Proyek Pembangunan RS Banyumanik II

Tabel 1. Tabel Waktu Pelaksanaan Proyek Pembangunan RS Banyumanik II

\begin{tabular}{|c|c|c|c|c|c|}
\hline No & Task Name & $\begin{array}{l}\text { Waktu } \\
\text { (Hari) }\end{array}$ & No & Task Name & $\begin{array}{l}\text { Waktu } \\
\text { (Hari) }\end{array}$ \\
\hline 1 & Pekerjaan Persiapan & 7 & 18 & Kolom praktis 11 x $11 \mathrm{lt} 1$ & 28 \\
\hline 2 & Pemadatan tanah per $20 \mathrm{~cm}$ & 14 & 19 & Plat Kanopi $\mathrm{t}=10 \mathrm{~cm} \mathrm{lt} 1$ & 28 \\
\hline 3 & $\begin{array}{l}\text { Galian Tanah Footplate dan } \\
\text { Pedestal }\end{array}$ & 14 & 20 & Plat lantai $\mathrm{t}=15 \mathrm{~cm} \mathrm{lt} 2$ & 28 \\
\hline 4 & $\begin{array}{l}\text { Lantai kerja beton } \mathrm{K} 175 \mathrm{t}=10 \\
\mathrm{~cm}\end{array}$ & 28 & 21 & Tangga beton lt 2 & 42 \\
\hline 5 & Galian Tanah Sloof & 14 & 22 & Plat lantai $\mathrm{t}=15 \mathrm{~cm} \mathrm{lt} 3$ & 28 \\
\hline 6 & Pile Cap dan Footplate & 28 & 23 & Kolom struktur lt 3 & 49 \\
\hline 7 & $\begin{array}{l}\text { Urugan Kembali Footplate dan } \\
\text { Pedestal }\end{array}$ & 14 & 24 & Balok induk lt 3 & 45 \\
\hline 8 & Pedestal struktur lt 1 & 21 & 25 & $\begin{array}{l}\text { Beton kolom praktis } 11 \mathrm{x} \\
11 \text { lt } 2\end{array}$ & 28 \\
\hline 9 & Sirtu $\mathrm{t}=5 \mathrm{~cm}$ & 14 & 26 & Balok Lantai 10 x 15 lt 2 & 30 \\
\hline 10 & Sloof lt1 & 28 & 27 & Plat Kanopi $\mathrm{t}=10 \mathrm{~cm} \mathrm{lt} 2$ & 28 \\
\hline 11 & Pemadatan tanah per $20 \mathrm{~cm}$ & 14 & 28 & pekerjaan atap & 45 \\
\hline 12 & Kolom struktur lt 1 & 49 & 29 & Plat Atap $t=15$ lt 3 & 44 \\
\hline 13 & Balok induk lt 1 & 42 & 30 & Tangga beton lt 3 & 43 \\
\hline 14 & Tangga lt 1 & 28 & 31 & Balok Lantai $10 \times 15$ lt 3 & 30 \\
\hline 15 & Balok induk lt 2 & 42 & 32 & Kolom praktis 11 x 11 lt 3 & 28 \\
\hline 16 & Kolom struktur lt 2 & 49 & 33 & Plat Kanopi $\mathrm{t}=10 \mathrm{~cm} \mathrm{lt} 3$ & 28 \\
\hline 17 & Balok Lantai 10x15 lt 1 & 28 & 27 & Plat Kanopi $\mathrm{t}=10 \mathrm{~cm} \mathrm{lt} 2$ & 28 \\
\hline
\end{tabular}

Pengukuran Performansi Proyek Menggunakan Metode Earned Value Analysis

Proses pengukuran performansi proyek dilakukan dengan membandingkan data-data pada saat monitoring pada bulan November 2015 dengan data pada perencanaan. Gambar 2 menggambarkan progres proyek hingga hari ke 315 


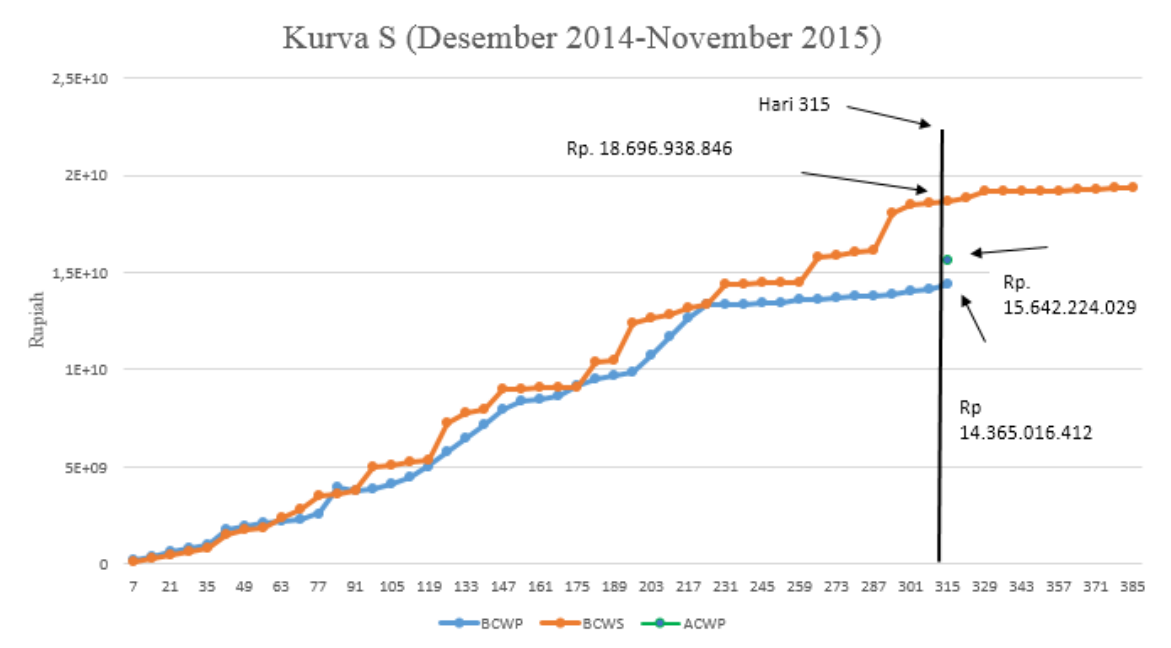

Gambar 2. Kurva S Proyek Pembangunan RS Banyumanik Hari ke 315

Berdasarkan data pada gambar 2 didapatkan bahwa nilai BCWS sebesar Rp. 18.969.938.846 (96,581\% x Rp 19.358.816.791,79), nilai ACWP sebesar Rp. 15.642.224.029, dan nilai BCWP sebesar Rp. 14.365.016.412 (74,204\%x Rp 19.358.816.791,79)

\section{Variansi Waktu}

Dengan menggunakan rumus (1) didapatkan hasil pengukuran variansi waktu (SV) sebesar minus Rp.4.331.922.433 (Rp 14.365.016.412- Rp 18.696.938.846). Nilai negatif pada perhitungan variansi waktu menunjukkan bahwa kinerja pekerjaan buruk. Hal ini menunjukkan bahwa biaya aktual lebih besar dari rencana jadwal yang telah disusun. Setelah mendapat variansi waktu, nilai SPI dapat dihitung dengan menggunakan rumus (4). Perhitungan nilai SPI mendapatkan hasil 0,768 (Rp 14.365.016.412 / Rp 18.696.938.846). Nilai ini kurang dari satu; menunjukkan bahwa kinerja dari proyek pembangunan Rumah Sakit Banyumanik II tidak sesuai dengan yang diharapkan karena tidak mampu mencapai target yang telah ditetapkan.

\section{Variansi Biaya}

Dengan menggunaan rumus (2), didapatkan hasil pnegukuran variansi biaya (CV) sebesar minus Rp.1..277.207.617 (Rp 14.365.016.412 - $\mathrm{Rp}$ 15.642.224.029). Hasil negatif pada perhitungan variansi biaya menunjukkan bahwa biaya yang telah dikeluarkan melebihi nilai aktual pekerjaan yang telah dicapai. Selanjutnya, dengan menggunakan rumus (6) didapat nilai untuk CPI sebesar 0,918 (Rp 14.365.016.412/Rp 15.642.224.029). Nilai ini lebih kecil dari satu yang nenunjukkan bahwa kinerja biaya buruk terdapat pemborosan dalam menyelesaikan proyek.

\section{Perkiraan Biaya dan Waktu Akhir Pengerjaan Proyek Berdasrkan Kinerja Proyek pada Hari Ke-315}

Perkiraan biaya penyelesaian akhir dari proyek (EAC) berdasarkan kinerja proyek pada hari ke 315 dapat dicari menggunakan rumus (8) dan diperoleh EAC sebesar Rp. 21.080.028.070 (Rp 15.642.224.029 + Rp 5.437.804.041). Selanjutnya, perkiraan waktu penyelesaian proyek (ECD) dapat dihitung dengan menggunakan rumus (11). Berdasarkan hasil perhitungan nilai ECD, jika kinerja proyek tidak berubah, sisa kegiatan dalam proyek akan dapat diselesaikan dalam kurun waktu 118 hari atau proyek akan selesai pada tanggal 14 Mei $2016((55 / 0,768)+$ 29 Desember 2014).

Jika proyek diinginkan untuk tetap selesai sesuai dengan biaya yang telah dianggarkan, maka hal ini dapat diperkirakan dengan menghitung TCPI menggunakan rumus (14). Hasil perhitungan menunjukkan nilai TPCI sebesar 1,344 $\left(\frac{\text { Rp.19.358.816.791,79-Rp14.365.016.412 }}{\text { Rp.19.358.816.791,79-Rp15.642.224.029 }}\right)$, Angka sebesar 1,344 menunjukkan bahwa kinerja biaya pada hari ke 315 sebesar 0,918 harus ditingkatkan menjadi 1,344 agar proyek dapat selesai sesuai dengan anggaran.

\section{Penentuan Waktu yang Diharapkan Menggunakan PERT}

Pada hari ke 315, proyek telah menyelesaikan kolom struktur lantai 3 sehingga menyisakan kegiatan dengan waktu optimis, most likely, dan pesimis untuk kegatan-kegiatan lainnya sebagaimana tampak pada lampiran 1. Secara grafis, gambaran kegiatan yang tersisa dari proyek dapat dilihat pada gambar 3 berikut. 


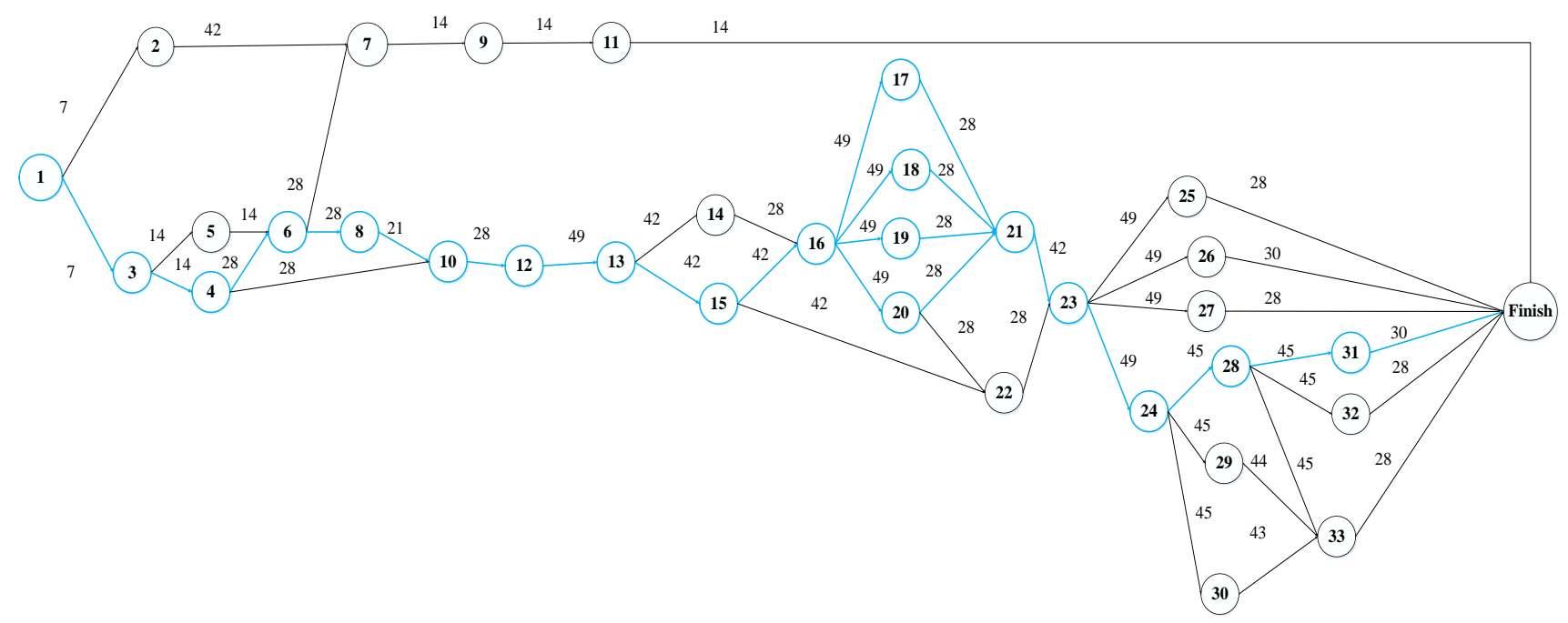

Gambar 3. Jalur Lintasan Kritis Proyek Pembangunan RS Banyumanik II

\section{Analisa Waktu Percepatan Kegiatan}

Percepatan waktu pelaksanaan proyek pembangunan RS Banyumanik II dihasilkan dengan mempercepat kegiatan-kegiatanyang berada pada linatasan kritis yang belum terlaksana. Secara rinci, iterasi yang menggambarkan percepatan yang dilakukan untuk setiap aktivitas dan biaya yang ditimbulkan dari percepatan tersebut dapat dilihat pada lampiran 6, Jika sisa kegiatan proyek dipercepat dan proyek dapat diselesaikan dalam kurun waktu 117 hari, maka total biaya yang diperlukan adalah Rp.4.787.828.482, Jika sisa kegiatan proyek dipercepat dan proyek dapat diselesaikan dalam kurun waktu 113 hari, maka biaya yang diperlukan adalah Rp $\quad 4.800 .288 .482$, Jika sisa kegiatan proyek dipercepat dan proyek dapat diselesaikan dalam kurun waktu 103 hari, maka biaya yang diperlukan adalah Rp.5.014.688.482. Jika sisa kegiatan proyek dipercepat dan proyek dapat diselesaikan dalam kurun waktu 102 hari, maka baiya yang diperlukan adalah Rp.5.053.453.482; dan jika sia kegiatan proyek dipercepat dan proyek dapat diselesaikan dalam kurun waktu 94 hari maka biaya yang diperlukana adalah Rp.5.397.573.482.

\section{Kesimpulan}

Berdasarkan perhitungan dan analisa yang dilakukan, maka dapat diperoleh kinerja pelaksanaan proyek pembangunan Rumah Sakit Banyumanik II pada hari ke 315 menunjukkan kondisi yang buruk. Dalam hal ini, perbandingan antara kemajuan penyelesaian proyek dengan pencapaian yang direncanakan bernilai kurang dari 1, yaitu hanya $76,8 \%$ Perbandingan antara biaya yang telah dikeluarkan dengan nilai yang didapat hingga pada hari ke 315 bernilai kurang dari 1, yaitu 91,8\%.

Hasil perhitungan dengan menggunakan EVA menunjukkan bahwa sisa kegiatan dalam proyek diperkirakan akan dapat diselesaikan dalam kurun waktu 118 hari atau pada tanggal 14 Mei 2016 apabila kondisi kinerja proyek seperti pada saat pelaporan ini dibuat. Dalam hal ini, proyek akan terlambat dari target awal, yaitu pada tanggal 17 Januari 2016. Selain mengalami keterlambatan jadwal proyek akan mengalami pembengkakkan biaya. Proyek diperkirakan akan memerlukan dana penyelesaian sebesar Rp 21.080.028.070 atau proyek akan kekurangan dana sebesar Rp 1.721.211.278,13 dari anggaran awal yang telah ditetapkan sebesar Rp19.358.816.791,79.

Berdasarkan hasil perhitungan dengan menggunakan metoda PERT dapat disimpulkan bahwa, jika sisa kegiatan proyek dipercepat dan proyek dapat diselesaikan dalam kurun waktu 117 hari, maka total biaya yang diperlukan adalah Rp.4.787.828.482, Jika sisa kegiatan proyek dipercepat dan proyek dapat diselesaikan dalam kurun waktu 113 hari, maka biaya yang diperlukan adalah $\mathrm{Rp} \quad 4.800 .288 .482$, Jika sisa kegiatan proyek dipercepat dan proyek dapat diselesaikan dalam kurun waktu 103 hari, maka biaya yang diperlukan adalah Rp.5.014.688.482. Jika sisa kegiatan proyek dipercepat dan proyek dapat diselesaikan dalam kurun waktu 102 hari, maka baiya yang diperlukan adalah Rp.5.053.453.482; dan jika sia kegiatan proyek dipercepat dan proyek dapat diselesaikan dalam kurun waktu 94 hari maka biaya yang diperlukana adalah Rp.5.397.573.482

\section{Daftar Pustaka}

Adegoke, A.S. (2011). Measuring process effectiveness using CPM/PERT. International Journal of Business and Management, 6(6), 286.

Burke R. (2006). Project Management. Planning and Control Techniques. John Wiley \& Sons.

Cleland, D. I., \& Ireland, L. R. (1994). Project management: strategic design and implementation (Vol. 4). New York: McGraw-Hill. 
Doubravský, K., \& Doskočil, R. (2013). Risk Analysis of Stochastic PERT Graph. Trends Economics and Management, 7(14), 35-43.

Ervianto, \& Wulfram I. (2004)., Manajemen Proyek Konstruksi Edisi Pertama, Salemba Empat, Yogyakarta

Hall, N. G. (2012). Project management: Recent developments and research opportunities. Journal of Systems Science and Systems Engineering, 21(2), 129-143.

Khamooshi, H., \& Golafshani, H. (2014). EDM: Earned Duration Management, a new approach to schedule performance management and measurement. International Journal of Project Management, 32(6), 10191041.

Larson, E.W., \& Gray, C.F. (2011) Project Management The Managerial Process. fifth edition, New York : McGraw Hill Professional 2010

Naderpour, A., \& Mofid, M. (2011). Improving construction management of an educational center by applying earned value technique. Procedia engineering, 14, 1945-1952.

Shtub, A., Bard, J. F., \& Globerson, S. (1994). Project management: engineering, technology, and implementation. PrenticeHall, Inc..

Verma, A., Pathak, K. K., \& Dixit, R. K. (2014). Earned Value Analysis of Construction Project at Rashtriya Sanskrit Sansthan, Bhopal. International Journal of Innovative Research in Science, Engineering and Technology,3(4), 11350-11355.

Vanhoucke, M. (2012). Project management with dynamic scheduling. Berling Heidelberg: Spirnger

Lampiran 1

Tabel Data Waktu Optimis, Realis, dan Pesemis Kegiatan Belum Terlaksana

\begin{tabular}{lllll}
\hline \multirow{2}{*}{ No } & Task Name & Waktu (Hari) & & \\
24 & Optimis & Realistis & Pesimis \\
25 & Balok induk lt 3 & 35 & 42 & 65 \\
26 & Balok Lantai 10 x 15 lt 2 & 20 & 28 & 35 \\
27 & Plat Kanopi t $=10 \mathrm{~cm} \mathrm{lt} \mathrm{2}$ & 24 & 28 & 42 \\
28 & pekerjaan atap & 20 & 28 & 35 \\
29 & Plat Atap t $=15$ lt 3 & 35 & 42 & 65 \\
30 & Tangga beton lt 3 & 33 & 42 & 60 \\
31 & Balok Lantai 10 x 15 lt 3 & 30 & 42 & 60 \\
32 & Kolom praktis 11 x 11 lt 3 & 24 & 28 & 42 \\
33 & Plat Kanopi t = 10 cm lt 3 & 20 & 28 & 35 \\
\hline
\end{tabular}

Lampiran 2

Tabel Data Cost Slope Kegiatan Proyek Belum Terlaksana

\begin{tabular}{|c|c|c|c|c|c|c|c|}
\hline \multirow[b]{2}{*}{ No } & \multirow[b]{2}{*}{ Unit Kegiatan } & \multicolumn{2}{|c|}{ Waktu (Hari) } & \multicolumn{3}{|l|}{ Biaya (Rp) } & \multirow{2}{*}{ Cost Slope } \\
\hline & & Normal & $\begin{array}{l}\text { Percepa } \\
\text { tan }\end{array}$ & Normal & $\begin{array}{l}\text { Total } \\
\text { akselerasi }\end{array}$ & $\begin{array}{l}\text { biaya akselerasi } \\
\text { perhari }\end{array}$ & \\
\hline 24 & Balok Induk Lt 3 & 45 & 35 & 1.727 .047 .421 & 1.947 .247 .421 & 22.020 .000 & 6.291 .429 \\
\hline 25 & $\begin{array}{l}\text { Beton Kolom Praktis } 11 \\
\text { X } 11 \text { Lt } 2\end{array}$ & 28 & 20 & 18.305 .549 & 29.225 .549 & 1.365 .000 & 546.000 \\
\hline 26 & Balok Lantai 10 X 15 Lt 2 & 30 & 24 & 26.438 .212 & 35.078 .212 & 1.440 .000 & 360.000 \\
\hline 27 & $\begin{array}{l}\text { Plat Kanopi } \mathrm{T}=10 \mathrm{Cm} \mathrm{Lt} \\
2\end{array}$ & 28 & 20 & 45.585 .151 & 52.705 .151 & 890.000 & 356.000 \\
\hline 28 & Pekerjaan Atap & 45 & 35 & 17.979 .980 & 28.379 .980 & 1.040 .000 & 297.143 \\
\hline 29 & Plat Atap T $=15$ Lt 3 & 44 & 33 & 2.639.217.533 & 3.060 .572 .533 & 38.305 .000 & 12.768 .333 \\
\hline 30 & Tangga Beton Lt 3 & 43 & 30 & 112.144 .060 & 167.394 .060 & 4.250 .000 & 1.841 .667 \\
\hline 31 & Balok Lantai 10 X 15 Lt 3 & 30 & 24 & 26.438 .212 & 35.078 .212 & 1.440 .000 & 360.000 \\
\hline 32 & $\begin{array}{l}\text { Kolom Praktis } 11 \text { X } 11 \mathrm{Lt} \\
3\end{array}$ & 28 & 20 & 24.746 .390 & 35.666 .390 & 1.365 .000 & 546.000 \\
\hline 33 & $\begin{array}{l}\text { Plat Kanopi } \mathrm{T}=10 \mathrm{Cm} \mathrm{Lt} \\
3\end{array}$ & 28 & 20 & 78.145 .973 & 85.265 .973 & 890.000 & 356.000 \\
\hline
\end{tabular}


Lampiran 3

\begin{tabular}{|c|c|c|c|c|c|c|c|c|}
\hline \multirow{2}{*}{ No } & \multirow{2}{*}{ Kegiatan } & \multicolumn{2}{|c|}{ Durasi (Minggu) } & \multicolumn{2}{|c|}{ Pekerja (Orang) } & \multicolumn{2}{|c|}{ Biaya Langsung (Rp) } & \multirow{2}{*}{$\begin{array}{l}\text { Biaya Tdk Langsung } \\
\text { (Rp) }\end{array}$} \\
\hline & & Normal & Mak Crashing & Keterangan & Jml Pekerja/Hari & Biaya & Total & \\
\hline \multirow{7}{*}{25} & \multirow{7}{*}{$\begin{array}{l}\text { Balok lantai lt } \\
2\end{array}$} & \multirow{7}{*}{30} & \multirow[t]{7}{*}{8} & Pekerja & 3 & 75000 & 225000 & \multirow{19}{*}{580000} \\
\hline & & & & Tukang batu & 1 & 100000 & 100000 & \\
\hline & & & & Tukang kayu & 1 & 100000 & 100000 & \\
\hline & & & & Tukang besi & 1 & 100000 & 100000 & \\
\hline & & & & Kepala tukang & 1 & 120000 & 120000 & \\
\hline & & & & Mandor & 1 & 150000 & 150000 & \\
\hline & & & & Sub Total & & 795.000 & & \\
\hline \multirow{7}{*}{26} & \multirow{7}{*}{$\begin{array}{l}\text { Beton kolom } \\
\text { praktis lt } 2\end{array}$} & \multirow{7}{*}{28} & \multirow{7}{*}{24} & Pekerja & 3 & 75000 & 225000 & \\
\hline & & & & Tukang batu & 1 & 100000 & 100000 & \\
\hline & & & & Tukang kayu & 1 & 100000 & 100000 & \\
\hline & & & & Tukang besi & 1 & 100000 & 100000 & \\
\hline & & & & Kepala tukang & 1 & 120000 & 120000 & \\
\hline & & & & Mandor & 1 & 150000 & 150000 & \\
\hline & & & & Sub Total & & 795.000 & & \\
\hline \multirow{5}{*}{27} & \multirow{5}{*}{$\begin{array}{l}\text { Plat Kanopi } \mathrm{t} \\
=10 \mathrm{~cm} \mathrm{lt} 2\end{array}$} & \multirow{5}{*}{28} & \multirow{5}{*}{20} & Pekerja & 1 & 75000 & 75000 & \\
\hline & & & & Tukang Kayu & 1 & 100000 & 100000 & \\
\hline & & & & Kepala Tukang & 1 & 120000 & 120000 & \\
\hline & & & & Mandor & 1 & 150000 & 150000 & \\
\hline & & & & Sub Total & & 445.000 & & \\
\hline
\end{tabular}

Lanjutan lampiran 3

\begin{tabular}{|c|c|c|c|c|c|c|c|c|c|}
\hline \multirow{2}{*}{ No } & \multirow{2}{*}{ Kegiatan } & \multicolumn{2}{|c|}{ Durasi (Minggu) } & \multicolumn{2}{|c|}{ Pekerja (Orang) } & \multicolumn{2}{|c|}{ Biaya Langsung (Rp) } & \multirow{2}{*}{$\begin{array}{ll}\begin{array}{l}\text { Biaya } \\
\text { (Rp) }\end{array} & \text { Tdk } \\
\end{array}$} & \multirow[t]{2}{*}{ Langsung } \\
\hline & & Normal & Mak Crashing & Keterangan & Jml Pekerja/Hari & Biaya & Total & & \\
\hline \multirow{7}{*}{24} & \multirow{7}{*}{$\begin{array}{l}\text { Beton } \\
\text { balok } \\
\text { induk lt } 3\end{array}$} & \multirow{7}{*}{ Normat } & \multirow[t]{7}{*}{0} & Pekerja & 99 & 75000 & 7425000 & \multirow{11}{*}{580.000} & \\
\hline & & & & Tukang Batu & 2 & 100000 & 200000 & & \\
\hline & & & & Kepala Tukang & 9 & 120000 & 1080000 & & \\
\hline & & & & Mandor & 7 & 150000 & 1050000 & & \\
\hline & & & & Tukang Besi & 60 & 100000 & 6000000 & & \\
\hline & & & & Tukang kayu & 15 & 100000 & 1500000 & & \\
\hline & & & & $\begin{array}{l}\text { Sub Total } \\
\text { Pekerja }\end{array}$ & 2 & $\begin{array}{l}\mathbf{1 7 2 5 5 0 0 0} \\
75000\end{array}$ & 150000 & & \\
\hline \multirow{4}{*}{28} & \multirow{4}{*}{$\begin{array}{l}\text { Pek Atap } \\
\text { Dan Atap }\end{array}$} & \multirow{4}{*}{45} & \multirow{4}{*}{35} & Tukang Kayu & 2 & 100000 & 200000 & & \\
\hline & & & & Kepala Tukang & 2 & 120000 & 240000 & & \\
\hline & & & & Mandor & 2 & 150000 & 300000 & & \\
\hline & & & & Sub Total & & 890000 & & & \\
\hline
\end{tabular}




\begin{tabular}{|c|c|c|c|c|c|c|c|}
\hline \multirow{7}{*}{29} & \multirow{7}{*}{$\begin{array}{l}\text { Beton plat } \\
\text { atap } t=15 \\
\text { lt } 3\end{array}$} & \multirow{7}{*}{42} & \multirow{7}{*}{33} & Pekerja & 163 & 75000 & 12225000 \\
\hline & & & & Tukang Batu & 19 & 100000 & 1900000 \\
\hline & & & & Kepala Tukang & 15 & 120000 & 1800000 \\
\hline & & & & Mandor & 10 & 150000 & 1500000 \\
\hline & & & & Tukang Besi & 3 & 100000 & 300000 \\
\hline & & & & Tukang kayu & 19 & 100000 & 1900000 \\
\hline & & & & Sub Total & & 19625000 & \\
\hline
\end{tabular}

Lanjutan lampiran 3

\begin{tabular}{|c|c|c|c|c|c|c|c|c|}
\hline \multirow[b]{2}{*}{ No } & \multirow[b]{2}{*}{ Kegiatan } & \multicolumn{2}{|c|}{ Durasi (Minggu) } & \multicolumn{2}{|l|}{ Pekerja (Orang) } & \multicolumn{2}{|c|}{ Biaya Langsung (Rp) } & \multirow{2}{*}{$\begin{array}{l}\text { Biaya Tidak } \\
\text { Langsung (Rp) }\end{array}$} \\
\hline & & Normal & Mak Crashing & Keterangan & $\begin{array}{l}\text { Jumlah } \\
\text { Pekerja/Hari }\end{array}$ & Biaya & Total & \\
\hline \multirow{7}{*}{30} & \multirow{7}{*}{ tangga beton lt 3} & \multirow{7}{*}{42} & \multirow{7}{*}{30} & Pekerja & 12 & 75000 & 900000 & \multirow{21}{*}{580.000} \\
\hline & & & & Tukang Batu & 1 & 100000 & 100000 & \\
\hline & & & & Kepala Tukang & 3 & 120000 & 360000 & \\
\hline & & & & Mandor & 3 & 150000 & 450000 & \\
\hline & & & & Tukang Besi & 10 & 100000 & 1000000 & \\
\hline & & & & Tukang kayu & 1 & 100000 & 100000 & \\
\hline & & & & Sub Total & & 2.910 .000 & & \\
\hline \multirow{7}{*}{31} & \multirow{7}{*}{ Balok lantai lt 3} & \multirow{7}{*}{28} & \multirow{7}{*}{24} & Pekerja & 99 & 75000 & 7425000 & \\
\hline & & & & Tukang batu & 2 & 100000 & 200000 & \\
\hline & & & & Tukang kayu & 15 & 100000 & 1500000 & \\
\hline & & & & Tukang besi & 60 & 100000 & 6000000 & \\
\hline & & & & Kepala tukang & 9 & 120000 & 1080000 & \\
\hline & & & & Mandor & 7 & 150000 & 1050000 & \\
\hline & & & & Sub Total & & 17.255 .000 & & \\
\hline \multirow{7}{*}{32} & \multirow{7}{*}{$\begin{array}{ll}\text { Beton } & \text { kolom } \\
\text { praktis lt } 3 & \end{array}$} & \multirow{7}{*}{28} & \multirow{7}{*}{20} & Pekerja & 3 & 75000 & 225000 & \\
\hline & & & & Tukang batu & 1 & 100000 & 100000 & \\
\hline & & & & Tukang kayu & 1 & 100000 & 100000 & \\
\hline & & & & Tukang besi & 1 & 100000 & 100000 & \\
\hline & & & & Kepala tukang & 1 & 120000 & 120000 & \\
\hline & & & & Mandor & 1 & 150000 & 150000 & \\
\hline & & & & Sub Total & & 795.000 & & \\
\hline
\end{tabular}


Lanjutan lampiran 5

\begin{tabular}{|c|c|c|c|c|c|c|c|c|}
\hline \multirow[b]{2}{*}{ No } & \multirow[b]{2}{*}{ Kegiatan } & \multicolumn{2}{|c|}{ Durasi (Minggu) } & \multicolumn{2}{|c|}{ Pekerja (Orang) } & \multicolumn{2}{|c|}{ Biaya Langsung (Rp) } & \multirow[b]{2}{*}{$\begin{array}{l}\text { Biaya Tidak } \\
\text { Langsung (Rp) }\end{array}$} \\
\hline & & Normal & $\begin{array}{l}\text { Maksimal } \\
\text { Crashing }\end{array}$ & Keterangan & $\begin{array}{l}\text { Jumlah } \\
\text { Pekerja/Hari }\end{array}$ & Biaya & Total & \\
\hline \multirow{5}{*}{33} & \multirow{5}{*}{ Plat kanopi lt 3} & \multirow{5}{*}{28} & \multirow{5}{*}{ Crasiming } & Pekerja & 1 & 75000 & 75000 & \multirow{5}{*}{580000} \\
\hline & & & & Tukang Kayu & 1 & 100000 & 100000 & \\
\hline & & & & Kepala & 1 & 120000 & 120000 & \\
\hline & & & & Mandor & 1 & 150000 & 150000 & \\
\hline & & & & $\begin{array}{l}\text { Sub Total } \\
\text { Total }\end{array}$ & & 445000 & 83195000 & \\
\hline
\end{tabular}

Lampiran 6

Tabel Rekap Durasi Dan Biaya Proses Crashing Proyek Pembangunan RS Banyumanik II

\begin{tabular}{|c|c|c|c|c|}
\hline Iterasi & Kegiatan & $\begin{array}{l}\text { Durasi } \\
\text { penyelesiaian } \\
\text { (Hari) }\end{array}$ & Biaya & Penyelesaian \\
\hline 0 & - & 120 & $\mathrm{Rp}$ & 4.716 .048 .482 \\
\hline 1 & Pekerjaan atap & 119 & $\mathrm{Rp}$ & 4.717 .088 .482 \\
\hline 2 & $\begin{array}{l}\text { Balok Lantai lt } 3 \\
\text { Balok Lantai lt } 3\end{array}$ & 117 & $\mathrm{Rp}$ & 4.719 .968 .482 \\
\hline 3 & $\begin{array}{l}\text { Kolom praktis it } 3 \\
\text { Plat kanopi it } 3\end{array}$ & 113 & $\mathrm{Rp}$ & 4.734 .748 .482 \\
\hline 4 & Balok induk lt 3 & 103 & $\mathrm{Rp}$ & 4.954.948.482 \\
\hline 5 & $\begin{array}{l}\text { Pekerjaan atap } \\
\text { plat atap lt } 3 \\
\text { Pekerjaan atap }\end{array}$ & 102 & $\mathrm{Rp}$ & 4.994.293.482 \\
\hline 6 & $\begin{array}{l}\text { Plat atap lt } 3 \\
\text { Tangga beton lt } 3\end{array}$ & 94 & $\mathrm{Rp}$ & 5.343 .053 .482 \\
\hline
\end{tabular}

